\title{
PROCESSOS DE PRODUÇÃO DE COMPOSTOS DE LIXO E A SUA QUALIDADE COMO FERTILIZANTE ORGÂNICO
}

\section{PRODUCTION PROCESSES OF WASTE COMPOST AND ITS QUALITY AS ORGANIC FERTILIZER}

\section{Silva, F.C. ${ }^{1,6}$, Chitolina, J.C. ${ }^{2}$, Ballestero, S.D. ${ }^{3}$, Voigtel, S.D.S. ${ }^{4}$; Melo, J.R.B. ${ }^{5}$}

\begin{abstract}
${ }^{1}$ Embrapa Informática Agropecuária - Unicamp, Caixa Postal 6041, 13.083-970 Campinas, SP. e-mail: fcesar@cnptia.embrapa.br

${ }^{2}$ Escola de Engenharia de Piracicaba FUMEP, Av. Monsenhor Martinho Salgot 560 Piracicaba SP.

${ }^{3}$ Universidade de Taubaté, Av. 9 de Julho, no 199, Centro - Taubaté - SP. e-mail:sdbalest@ig.com.br

${ }^{4}$ Bióloga (Assessora Técnica) da Empresa Faber Serviço Ltda, Rua Duque de Caxias 188, sala 13, $2^{\circ}$ piso, Centro - São Sebastião - SP. e-mail:svoigtel@uol.com.br ${ }^{5}$ Gerente da Usina de Processamento de Lixo - URBAM, Município de S. José dos Campos, SP.

${ }^{6}$ Universidade de Campinas, Saneamento Ambiental - CESET, Rua Paschoal Marmo, 1888 -13.484-370 Limeira - SP. e-mail: fcesar@ceset.unicamp.br
\end{abstract}

\section{RESUMO}

A compostagem do lixo orgânico realizado de maneira correta apresenta ganhos reais à sociedade e benefícios incontestáveis para o gerenciamento público de resíduos sólidos no município. Os sistemas FABER-AMBRA ${ }^{\circledR}$ de pré-tratamento de resíduos sólidos domiciliares e DANO de compostagem de resíduo orgânico foram comparados, em termos de qualidade dos compostos orgânicos gerados para uso na agricultura. O sistema DANO utiliza um cilindro rotativo para acelerar a taxa inicial de compostagem e está sendo aplicado nas cidades de São José dos Campos e de São Paulo (Vila Leopoldina). Os materiais permanecem dentro dos bioestabilizadores por dois a três dias com velocidade de rotação superior a $1,5 \mathrm{rpm}$. O produto resultante é chamado de pré-composto e não possui qualidade suficiente para uso agrícola "in natura", devido a sua maturação incompleta e à carga patogênica elevada. Portanto, torna-se necessário terminar a compostagem em leiras, mantendo esses materiais nos pátios para atingir o nível de maturação aceitável para fins agrícolas. $\mathrm{Na}$ unidade de 
Vila Leopoldina, utiliza-se o processo DANO modificado com aumento na velocidade ou com menor período de permanência do material orgânico nos bioestabilizadores, necessitando assim, de um maior tempo nos pátios, para a maturação. O material bioestabilizado produzido pelo sistema FABER-AMBRA®, em São Sebastião-SP, com seis a nove meses de maturação, tem as características de maturidade adequadas para reduzir o volume e a carga orgânica e, conseqüentemente, aumentar a vida útil do aterro, possuindo, no entanto, teores de metais pesados altos para serem utilizados como fertilizantes orgânicos a serem aplicados na agricultura.

Palavras-chave: compostagem, resíduos sólidos urbanos, saneamento ambiental, metais pesados, agricultura.

\section{ABSTRACT}

The composting of organic waste may present real profits to the society and benefits for the solid residue public management in the city when it is correctly processed. The FABER-AMBRA system for domestic solid residue pre-treatment and DANO system for organic residue composting were compared based on organic composition quality generated for agricultural use. The DANO system is used at São José dos Campos and São Paulo City (Vila Leopoldina). The system uses rotating cylinder to accelerate the initial tax of compost. The material inside of the bioestabilizators for three days with rotating cylinder speed bigger than $1,5 \mathrm{rpm}$. The resultant product is called pre-compost and it does not have enough quality for agricultural use due to its maturation and pathogenic load. Therefore, it is necessary to keep the composting material outside in piles to reach an acceptable maturation level. The System DANO implemented in Vila Leopoldina unit was modified by increasing the rotating cylinder speed or decreasing the period of permanence of the organic material in the bioestabilizadors. Results shows that more time in the storage yard for maturation was necessary. The bioestabilizado material produced by the FABER-AMBRA ${ }^{\circledR}$ system implemented at São Sebastião city takes six to nine months of maturation. The compost has the characteristics of maturity necessary to reduce volume and the organic load increasing the useful life of landfills. However, it contains high concentration of heavy metal to be used as organic fertilizer.

Key words: composting, urban solid residues, environmental sanitation, heavy metals and agriculture.

\section{INTRODUÇÃO}

A rápida urbanização da população brasileira tem causado grande aumento no volumes de resíduos sólidos gerados nas cidades. O destino desses resíduos provoca grandes preocupações, pois seu descarte inadequado causa poluição ambiental (SILVA et al., 2002a). Uma solução para o problema do lixo é o processo de 
compostagem, que é uma forma de reciclagem, segundo a qual a matéria orgânica é transformada em fertilizante orgânico (JAHNEL et al, 1999), que pode ser utilizado para melhorar a fertilidade do solo (SILVA et al., 2002a).

A composição do lixo urbano varia em função do local de origem, mas de um modo geral, contém cerca de 500 a $600 \mathrm{~g} . \mathrm{kg}^{1}{ }^{1}$ de material orgânico, o qual pode ser aumentado com a coleta seletiva de lixo e destinado, pela compostagem, à produção de adubo orgânico (SILVA, 1999; KIEHL, 2003). Entretanto, os compostos de lixo possuem variações químicas amplas, devido às diferentes regiões geográficas: variação sazonal, diversidades de matérias primas e de usinas de compostagem com diferentes sistemas, tanto nas etapas de pré-tratamento como no controle do processamento (XIN et al., 1992). Esses autores compararam dados analíticos de compostos de lixo dos Estados Unidos e da Europa e constataram variações, tanto nos teores dos macro como no dos micro elementos, variações nos teores de umidade de 20 a $50 \%$, com matéria seca mantendo-se na faixa de $50 \%$. Os valores de $\mathrm{pH}$ mostraram-se neutros ou ligeiramente alcalinos.

Dentre os benefícios da compostagem, nota-se a diminuição do volume de lixo a ser depositado nos aterros sanitários e, em conseqüência, o aumento do tempo de vida útil destes. De acordo com Carlsson (2003), os aterros sanitários são sistemas de disposição que correspondem à opção menos adequada de tratamento do lixo, devido aos distúrbios ambientais causados pela emissão de gases poluentes e dos efluentes líquidos, além de apresentar um custo de implantação elevado.

Para a utilização do composto de lixo como adubo orgânico na agricultura, deve-se levar em consideração sua maturação. Tal propriedade determina o êxito da aplicação do composto. Essa fase do processo de compostagem pode ser feita de maneira bem simples, em processos denominados de sistemas abertos, nos quais a aeração é promovida pelo revolvimento do material em compostagem, ou em processos mais sofisticados, denominados sistemas fechados, em que o controle da oxigenação é feito através da circulação forçada. No sistema aberto, o material orgânico é amontoado em leiras, com seção triangular, as quais são revolvidas a intervalos de tempo, para promover a aeração do meio. O sistema fechado envolve o uso de reatores, que permitem melhor controle das condições de aeração, temperatura e umidade, mas apresenta custos mais elevados (MELO et al., 1997).

O período de maturação varia de acordo com os tipos de materiais utilizados para compostagem, podendo ser de dois a seis meses, produzindo, no final, um composto maduro e bem humificado (CRAVO, 1995; SILVA et al., 2002a). A utilização do composto curado como adubo orgânico possui efeitos benéficos nas propriedades físicas e químicas dos solos, em função do fornecimento de matéria orgânica, agindo físicamente como condicionador e contribuindo no aumento da disponibilidade de nutrientes às plantas (COSTA, 1998; HE et al,1997; WEIR e ZEIGER, 1997; CRAVO, 1995; SILVA et al., 2002a). 
De acordo com Hernando (1989), a aplicação de composto de lixo em quantidades superiores a $30 \mathrm{t} / \mathrm{ha}$, após 20 dias de aplicado no solo, ocasionou aumento na capacidade de retenção de água e aeração.

No Brasil, o fator que conduz a produção de compostos de baixa qualidade se relaciona principalmente com a presença de poluentes orgânicos e inorgânicos, e a melhoria deste produto seria pela prática da coleta seletiva do lixo domiciliar, na qual a obtenção do material não colocasse o meio ambiente em risco através de contaminações (GROSSI, 1993; EGREJA FILHO, 1993).

Portanto, esse fertilizante orgânico deve ser analisado, para verificar se em sua composição não há substâncias tóxicas e microrganismos patogênicos elevados, com riscos de contaminar os recursos naturais e afetar a saúde pública (SILVA et al., 2002a; KIEHL, 2003).

Em países Europeus e nos Estados Unidos, há regulamentos que controlam a presença de metais pesados no composto de lixo, estabelecendo limites máximos desses elementos para que o produto possa ser empregado na agricultura (GROSSI, 1993). O uso agrícola dos compostos de resíduos domiciliares é uma alternativa ambientalmente correta, porém a aplicação desse adubo orgânico no aumento da produtividade das culturas e na manutenção da conservação do solo, pressupõe uma boa qualidade, relacionada a uma coleta seletiva adequada, para evitar metais pesados no adubo.

O trabalho objetivou comparar os sistema Faber-Ambra, DANO original e modificado na produção de composto, a partir de resíduos sólidos orgânicos com utilização na agricultura e também as limitações ambientais e sanitárias de sua aplicação.

\section{MATERIAL E MÉTODOS}

Neste trabalho foi utilizada a metodologia dos quatro níveis da pesquisa, proposta por Libault (1971), dividida em quatro fases: a) copilatória ou de revisão de literatura; b) correlativa; c) semântico, e d) fase final ou normativa.

$\mathrm{Na}$ fase compilatória, ocorreu a geração de dados de pesquisa, nas usinas de compostagem do Estado de São Paulo, por meio de revisão bibliográfica.

As Usinas avaliadas periodicamente foram as localizadas em São Paulo (Vila Leopoldina e São Matheus - Processo DANO modificado) e São José dos Campos (DANO original). As amostras compostas foram coletadas em cada usina, durante dois anos consecutivos, com amostragens periódicas quinzenais, as quais se originaram de misturas de sub-amostras recebidas diariamente e acumuladas em uma caixa. A unidade de tratamento de São Sebastião utiliza o processo FABERAMBRA. Foram feitas 3 coletas em amostra composta, em três períodos de um mesmo ano.

Com as amostras compostas, se procedeu a uma pré-digestão, para eliminação da matéria orgânica, utilizando-se água oxigenada $\left(\mathrm{H}_{2} \mathrm{O}_{2}\right)$ a $30 \%$ e, posteriormente foi 
feita a solubilização do resíduo, com mistura nítrico-perclórica (CHITOLINA et al., 2001). Deste modo, procedeu-se à abertura, via mineralização dos elementos presentes nos compostos de lixo urbano, para fins de análises de $\mathrm{Al}, \mathrm{Ca}, \mathrm{Cd}, \mathrm{Cr}, \mathrm{Cu}$, $\mathrm{Fe}, \mathrm{Mg}, \mathrm{Mn}, \mathrm{Na}, \mathrm{Ni}, \mathrm{P}, \mathrm{Pb}$ e $\mathrm{Zn}$, em laboratórios, sendo determinados por espectrofotometria de plasma induzido em argônio (ICP-AES).

$\mathrm{Na}$ fase correlativa, ocorreu a análise dos dados levantados na fase anterior, sendo realizados testes estatísticos descritivos e correlações de Pearson (R), entre as variáveis dentro do mesmo agrupamento (usina).

A terceira fase, a semântica, ocorreu de forma interpretativa. Os dados anteriormente agrupados foram analisados, interpretados e estabelecidas as generalizações. A partir das generalizações, foram elaboradas propostas de divisões dos assuntos a serem tratados. A interpretação dos resultados conduziu a pesquisa para a sua fase final, ou seja, para a quarta fase, a normativa, chegando-se às propostas de aplicação dos resultados nas atividades concernentes às áreas de realização da pesquisa.

Para auxiliar a fase normativa, foi utilizado um sistema especialista para interpretar os resultados das análises dos compostos de lixo das usinas. Trata-se de um programa de computador que representa os conhecimentos de maneira similar aos especialistas. Foi construído pela equipe de pesquisa da Embrapa Informática Agropecuária, Faculdade de Engenharia Agrícola da UNICAMP e Instituto Agronômico de Campinas, denominado Sistema Inteligente para Recomendação do Composto de Lixo Urbano na Agricultura - SIRCLUA (SILVA et al., 2002b), o qual avalia em dois grupos de restrição: maturidade do CLU e fatores de risco ambiental.

Com base na segunda e terceira fases da proposta dos quatro níveis da pesquisa, foram realizadas visitas e entrevistas com os técnicos responsáveis pelas usinas de tratamento do lixo urbano nos três municípios, que utilizam diferentes sistemas de processamento e, assim, foram obtidas distintas qualidades dos compostos de lixo produzidos.

A qualidade dos compostos de lixo se expressa como condicionador das propriedades físicas, químicas e biológicas do solo e também como fornecedora de elementos essenciais à vida vegetal (BARREIRA, 2005). Os três sistemas de tratamento de lixo - compostagem avaliados foram: a) FABER-AMBRA ${ }^{\circledR}$ - Usina A, em São Sebastião-SP; b) DANO original, na URBAM (Usina B), localizado no município de São José dos Campos-SP e c) DANO reduzido, que apresenta uma modificação no tempo de retenção no interior do biodigestor e também por não se fazer a compostagem complementar nos pátios, processos realizados nas Usinas de Vila Leopoldina (Usina C) e de São Mateus (Usina D), localizadas na cidade de São Paulo-SP.

Tratamento Sistema Faber-Ambra ${ }^{\circledR}$ (Unidade de São Sebastião-SP) denominada de Usina A - esse processo foi desenvolvido pela Empresa Faber, com cooperação da Universidade de Braunschweig -Alemanha e foi concebido para minimizar os impactos causados ao meio ambiente, para estabilizar a matéria 
orgânica e reduzir em $40 \%$ o volume total, com grande diminuição na quantidade de chorume produzido e pouca formação de biogás $\left(\mathrm{CH}_{4}\right)$. Não tinha a finalidade de produzir composto (adubo orgânico) para ser aplicado na agricultura.

O processo FABER-AMBRA ${ }^{\circledR}$ encontra-se descrito em Voigtel (2002), basicamente é dividido em três etapas: a primeira é o Tratamento Mecânico I, que consiste na ruptura das sacolas plásticas, por meio de um tambor homogeneizador com aletas, descarga, triagem grosseira e umedecimento com chorume, passando em seguida para o Tratamento Biológico e, finalmente, para o Tratamento Mecânico II. No tratamento biológico o lixo é disposto em leiras, sobre estrados de madeira, ocorrendo a decomposição aeróbia de forma estática (Figura 1), com a aeração ocorrendo de forma passiva sem a utilização de nenhum tipo de compressor; esta se dá por convecção. Após a montagem das leiras, estas são recobertas por uma camada de material estabilizado, denominado biofiltro. O tratamento mecânico II ocorre após a estabilização da matéria orgânica e consiste da retirada e peneiramento do composto.

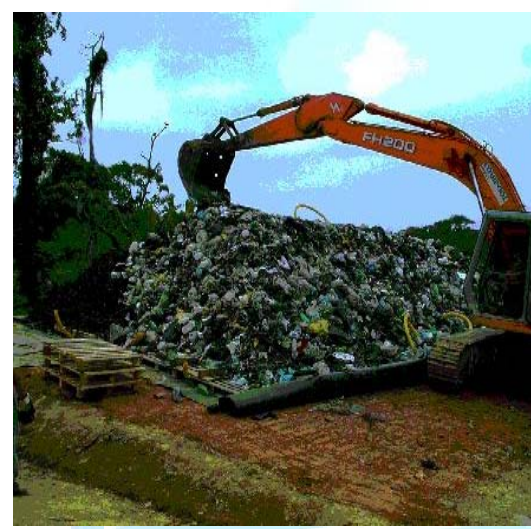

(a)

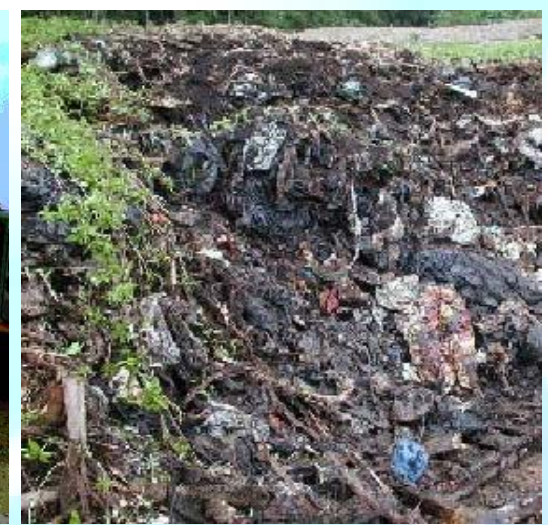

(b)

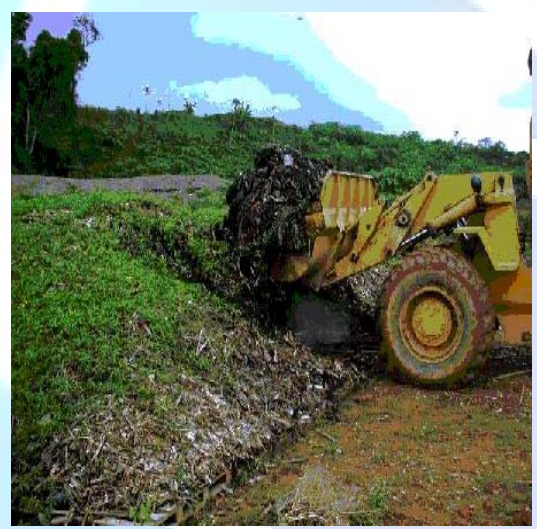

(c)

Figura 1- Etapas do Processo Faber-Ambra: (a) formação das leiras e disposição do lixo em estrado de madeira apoiado sobre uma lona plástica responsável pela coleta do líquido percolado chorume; (b) abertura de uma leira, com sacos de lixo depositados sobre o estrado e o material orgânico de cor escura e, (c) leira recoberta com material do biofiltro. Fotos: Soraya Voigtel

SISTEMA "DANO": É realizado através de cilindros bioestabilizadores e pilhas em pátios de maturação (Unidade da URBAM em São José dos Campos - SP), como se nota na Figura 2, e encontra-se descrito em Bidone e Povinelli (1999). É dividido em quatro fases: Seleção inicial; compostagem inicial; seleção final e compostagem final. Os bioestabilizadores são cilindros metálicos, com um diâmetro de 3,5 metros e um comprimento de 29 metros, dispostos horizontalmente e girando lentamente à velocidade de 1,0 rotação por minuto.

No projeto do Sistema Dano de Compostagem, com os Biodigestores girando a 1,0 rotação/minuto, funciona sob critérios técnicos que permite o correto 
funcionamento do controle interno da aeração e temperatura da massa de compostagem, o composto produzido era de péssima qualidade por não estar totalmente bioestabilizado. Isso ocorria devido à má interpretação de que o material já poderia ser extraído do bioestabilizador após 3 a 4 dias de retenção e que já poderia ser comercializado como um pré-composto orgânico.

No caso das unidades Paulistanas, que são as de Vila Leopoldina (Usina C) e São Matheus (Usina D), Bidone e Povinelli (1999) afirmam que a rotação do cilindro bioestabilizador foi aumentada de uma para duas rotações por minuto, permitindo assim que a concessionária aumentasse o processamento de $50 \mathrm{t} /$ dia, para $200 \mathrm{t} / \mathrm{dia}$ por cilindro. Com isso, o tempo de retenção do material dentro do cilindro foi reduzido de $48 \mathrm{~h}$, para menos de $8 \mathrm{~h}$, o que, levou a um controle insuficiente dos organismos patogênicos e à não estabilização da matéria orgânica gerando um composto com menor bioestabilização necessitando de maior tempo de biodegradação em pátios para a completa maturação.

Nesses processos, a fase ativa de degradação não era completada (material sem completa degradação) e a fase de maturação e humificação requeria mais 60 a 90 dias no pátio para se completar. A biodegradação complementar do processo de compostagem do pré-composto das Usinas C e D teria que ser realizada nas áreas dos produtores do cinturão verde de São Paulo.

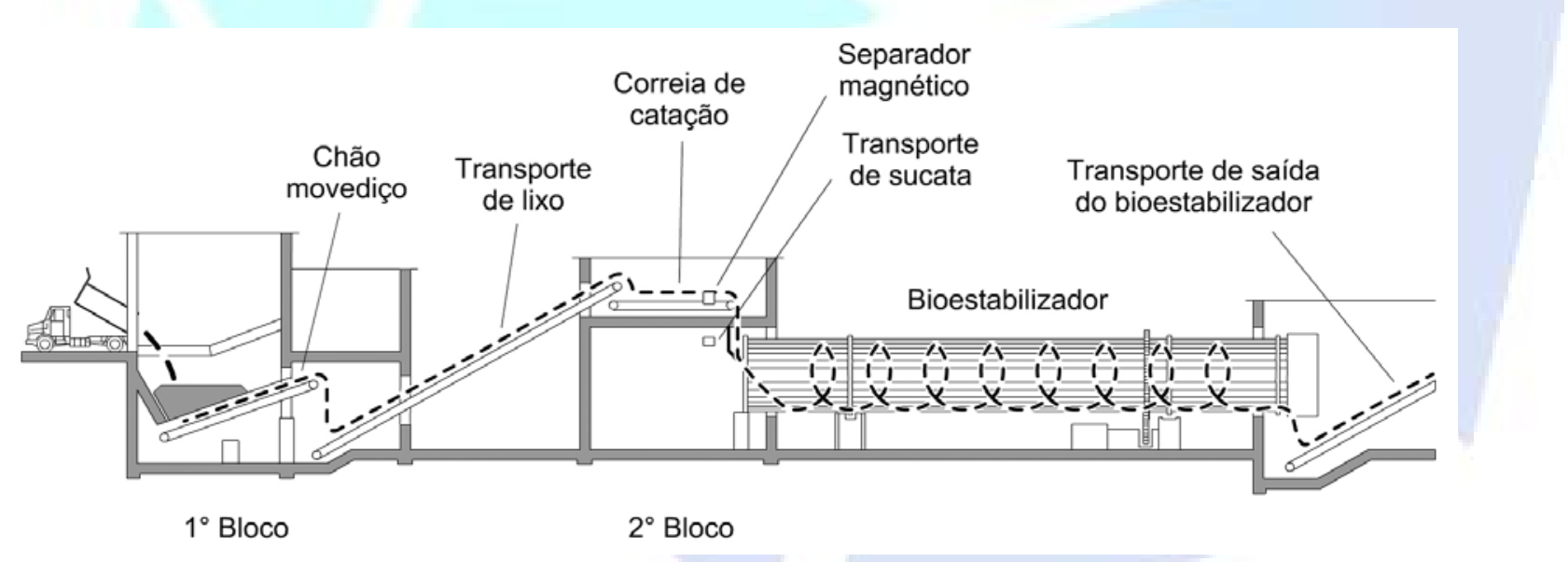

Figura 2- Sistema Dano de Compostagem do lixo (BARREIRA, 2005).

Na usina de tratamento de lixo da URBAM - Usina B, há um peneiramento que é feito após o período de maturação, em um conjunto de peneiras de dimensões menores de malha variável, que retira os inertes, melhorando a qualidade do adubo orgânico. Nessa usina o composto é de melhor qualidade, pois, após a passagem do material orgânico pelo cilindro bioestabilizador, é feita a maturação em pátios por 60 a 90 dias. 


\section{RESULTADOS E DISCUSSÃO}

Os compostos de lixo deste estudo, com as características físicas, químicas e biológicas apresentadas a seguir, correspondem à fase da seleção final do processo de produção. Representam valores médios de amostras coletadas num período de dois anos consecutivos de monitoramento (Tabela 1), os quais foram confrontados com valores limites de diversas legislações mundiais (PARR e HORNICK, 1992; GROSSI, 1983) e com pesquisas brasileiras (SILVA et al., 2002a). Os resultados foram aplicados ao sistema especialista SIRCLUA, desenvolvido por Silva et al (2002b), que traz conhecimentos sistematizados sobre o uso agrícola de composto de lixo. Tal sistema especialista foi organizado em duas fases, de acordo com as normas vigentes no Brasil, com a primeira dividida em dois grupos de restrição, como se nota na Figura 3: maturidade do CLU e fatores de risco ambiental.

A questão da maturidade do CLU consiste na avaliação de sua qualidade através da realização de análises químicas (SILVA et al., 2002b), com base em critérios, como: tipo de coleta do lixo, contaminação por patógenos e avaliação da qualidade do processo. De acordo com esse sistema, as usinas de São Matheus e Vila Leopoldina não atenderam aos critérios adotados no quesito da maturidade do composto, ou seja, o CLU apresentou um pH (água) maior que 6,5 e uma relação carbono/nitrogênio menor que 18 (JAHNEL et al., 1999), que não foi observado nos pré-compostos (SILVA et al., 2002a). Também foi insuficiente para o composto atingir os critérios padrões de maturação para uso agrícola, a saber: apresenta alta relação $\mathrm{C} / \mathrm{N}, 26: 1$, sendo que o ideal é na faixa de 10:1 a 15:1 no produto final, de acordo com Jahnel et al., 1999; matéria orgânica total 59,20\%, inferior a 40\% como o recomendado por Kiehl, 2003, para o uso agrícola e a quantidade de inertes é de $12,9 \%$, superior ao estabelecido por Silva et al, 2002a que está na faixa de 5 a $7 \%$. Na prática, o composto com alto valor de inertes proporciona a sensação de produto de má qualidade, o que reflete em baixo valor comercial (KIEHL, 2003). 


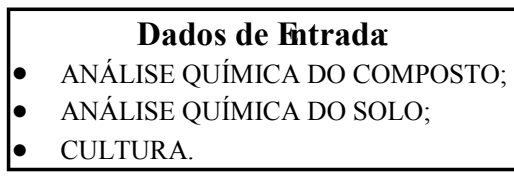

$1^{\circ}$ Etapa Avaliação da qualidade do CLU;

$2^{\circ}$ Etapa Recomendação de adubaçãœom CLU

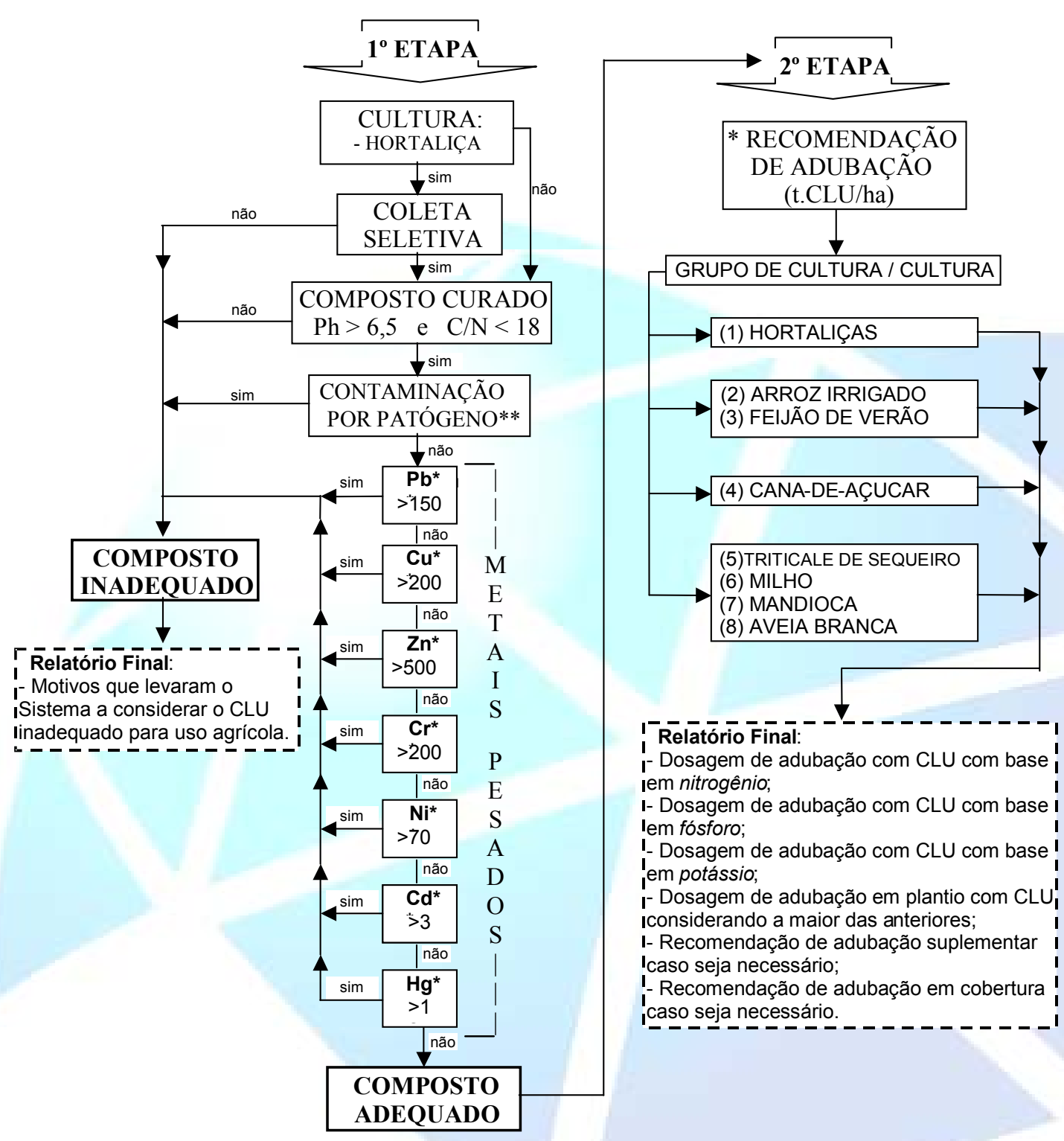

Figura 3- Diagrama da árvore de decisão deste Sistema Especialista, modificado de Silva et al. (2002b). *Ministério da Agricultura, Pecuária e Abastecimento (MAPA), da portaria $n^{\circ} 49$ de $25 / 04 / 2005 . * * n^{\circ}$ de salmonella sp $<3 \mathrm{NMP} / \mathrm{g}$ ST; $\mathrm{n}^{\circ}$ de Coliformes fecais $<1000 \mathrm{NMP} / \mathrm{g} \mathrm{ST} ; \mathrm{n}^{\circ}$ de ovos de helmintos $<$ $1 / 4 \mathrm{~g} \mathrm{ST}$.

Na primeira fase, ainda devem ser definidos os fatores de restrição ambiental e de saúde pública, verificando-se os limites permissíveis estipulados para cada metal pesado previsto pelo Ministério da Agricultura, Pecuária e Abastecimento (MAPA), 
na portaria $\mathrm{n}^{\circ} 49$ de 25/04/2005. Nas Tabelas 1 e 2, são apresentadas as concentrações de diversos elementos, presentes em diferentes compostos de lixo, estabelecidos pela portaria do MAPA e Silva et al. (2002a), como se nota na Figura 3, em que foram observados cuidados com o sistema de amostragem e métodos analíticos, para avaliar a concentração dos metais pesados. Os resultados referem-se às médias e às amplitudes (mínimo e máximo) dos valores centrais de análise de mais de 48 amostras de composto provenientes das usinas Paulistanas $\mathrm{C}$ e D e da usina do interior B, que foram coletadas sistematicamente, durante dois anos, para caracterizar esse material.

Assim, pode-se notar que as concentrações médias de metais pesados presentes nos materiais orgânicos produzidos pelas três usinas estiveram aquém das concentrações máximas estabelecidas no sistema especialista. Entretanto, a amplitude máxima obtida para alguns elementos presentes nos materiais orgânicos das Usinas $\mathrm{C}$ e D indica que algumas amostras do material orgânico apresentaram concentrações de metais pesados, além das concentrações máximas estabelecidas. Esses resultados sugerem a necessidade de um maior controle de qualidade do processo, a fim de que a presença de metais pesados no composto não restrinja o seu uso agrícola.

Avaliando os teores dos metais pesados $\mathrm{Cu}, \mathrm{Zn}, \mathrm{Cd}, \mathrm{Cr}, \mathrm{Ni}$, e $\mathrm{Hg}$ observa-se que as concentrações desses elementos estão abaixo dos valores médios determinados em amostras de composto de lixo analisadas em cidades do Estado de São Paulo. Os parâmetros internacionais de legislação servem como referência (PARR e HORNICK, 1992) na comparação com os dados obtidos nas usinas, assim como no trabalho de Silva et al (2002a). Nota-se que o composto pode ser aplicado em solos da Áustria, Itália, França e Suíça sendo proibido, no entanto, na Alemanha pela concentração de $\mathrm{Cu}$ e $\mathrm{Cd}$. Os valores mostrados indicam que a maior ocorrência é para o chumbo no "pré-composto" da Usina C, com mais de $20 \%$ das amostras apresentando concentrações desse elemento acima de $500 \mathrm{mg} \mathrm{kg}^{-1}$. Os metais presentes nos compostos seriam originários do processo de coleta, transporte e processamento dos resíduos, pois as baterias alcalinas de automóveis e pilhas acabam por vazar os seus conteúdos, liberando compostos de metais pesados, altamente tóxicos para seres humanos, plantas e animais (UEM/DEQ, 2004).

Quanto ao processo FABER-AMBRA da Usina A é um sistema que tem como objetivo fazer tratamento prévio dos resíduos domiciliares, dispondo os mesmos, após homogeneização, em leiras estáticas, com aeração passiva e, após sua estabilização, depositados em valas e/ou caixas de disposição, semelhante ao que é feito em aterros convencionais. Porém, estes são aterros já estabilizados havendo a minimização do ônus ambiental ligado à disposição dos resíduos através de estabilização em grande escala e não simplesmente o aterramento do lixo in natura. $\mathrm{Na}$ caracterização química e física de amostras do composto urbano proveniente da Usina A (Tabelas 1 e 2), de coletas após 4 a 9 meses de maturação em leiras estáticas aeradas naturalmente, podemos observar que o mesmo apresentou um resultado regular, em relação ao teor de matéria orgânica, ruim quanto à porcentagem de 
nitrogênio, bom para a relação $\mathrm{C} / \mathrm{N}, \mathrm{pH}$ e ótimo para a porcentagem de umidade, com base nos padrões de Silva et al. (2002a) e em padrões internacionais (PARR e HORNINCK, 1992).

Analisando os resultados, observa-se que o composto de lixo produzido pela usina A possui, em geral, teores de metais pesados dentro dos níveis de tolerância, com exceção do cádmio, que apresentou valores muito elevados, cuja origem, possivelmente, pode ser devido aos plásticos coloridos que são incluídos nas leiras de decomposição (PARR e HORNICK, 1992).

Tabela 1. Teores médios (mínimos e máximos) de elementos encontrados em précompostos de resíduos sólidos urbanos nas usinas de compostagem de lixo das Usinas de Vila Leopoldina (C) e de São Mateus (D) e do compostos maturados, produzidos na URBAM (B) e em São Sebastião (A).

\begin{tabular}{|c|c|c|c|c|c|}
\hline \multirow[b]{2}{*}{ Elemento } & \multicolumn{5}{|c|}{ Unidades de Reciclagem e Compostagem de RSU } \\
\hline & $\mathbf{D}$ & B & $\mathbf{C}$ & $\mathbf{A}$ & $\begin{array}{c}\text { Referência de } \\
\text { valores }^{(1)}\end{array}$ \\
\hline & & & g. $\mathrm{kg}^{-I}$ & & \\
\hline $\mathrm{N}$ & 13,2 & 11,5 & 12,5 & 8,5 a 10,0 & 9 a 10 (a) \\
\hline $\mathrm{P}$ & $9(4-14)$ & $8,5(6-11)$ & $8(3-10)$ & 3 a 5 & ---- \\
\hline $\mathrm{K}$ & $12(6-18)$ & $8(7-12)$ & $12(7-16)$ & 4 a 7 & ---- \\
\hline $\mathrm{Ca}$ & $47(24-68)$ & $45(42-59)$ & $51(14-50)$ & 39 a 44 & ---- \\
\hline $\mathrm{Mg}$ & $5(3-6)$ & $5(4-7)$ & $5(3-7)$ & 2 a 3 & ---- \\
\hline $\mathrm{Fe}$ & $20(16-28)$ & $15(13-25)$ & $15(13-25)$ & 40 a 65 & ---- \\
\hline $\mathrm{S}$ & $4(2,5-6,0)$ & $4,1(3,8-5,2)$ & $4,4(2,2-6,1)$ & 2,5 a 4 & ---- \\
\hline $\mathrm{Al}$ & $21(12-32)$ & $21(13-31)$ & $30(18-39)$ & 15 a 20 & ---- \\
\hline $\mathrm{Na}$ & $14(10-22)$ & $9(4-14)$ & $11(6-16)$ & 2 a 3 & $\begin{array}{l}3000(a) \\
2800(c) \\
\text { e } 2500(d)\end{array}$ \\
\hline $\begin{array}{l}\text { Cádmio } \\
\text { (Cd) }\end{array}$ & $1,8(0,3-3,7)$ & $1,9(0,7-5,0)$ & $\begin{array}{c}3,2(1,2- \\
10,1)\end{array}$ & 11 a 15 & $\begin{array}{l}5,0(\mathrm{a}) ; 6,0(\mathrm{~b}) \\
3,0(\mathrm{c}) \text { e } 1,5(\mathrm{~d})\end{array}$ \\
\hline Cromo (Cr) & $105(52-156)$ & 78 (38-97) & $85(33-239)$ & 7 a 14 & $\begin{array}{c}300(\mathrm{a}, \mathrm{d}) \mathrm{e} \\
100(\mathrm{~d})\end{array}$ \\
\hline Cobre $(\mathrm{Cu})$ & $356(112-584)$ & $167(87-217)$ & $\begin{array}{c}322(187- \\
621)\end{array}$ & 70 a 85 & $\begin{array}{c}500(\mathrm{a}) ; 300(\mathrm{~b}) \\
\text { e } 100(\mathrm{~d})\end{array}$ \\
\hline Manganes & $320(220-462)$ & $300(260-360)$ & $\begin{array}{c}345(208- \\
648)\end{array}$ & 250 a 300 & ---- \\
\hline Níquel (Ni) & $79(32-521)$ & $44(28-67)$ & $52(27-104)$ & 20 a 35 & $\begin{array}{c}100(\mathrm{a}) ; 200(\mathrm{~b}) \\
\text { e } 50(\mathrm{~d})\end{array}$ \\
\hline $\begin{array}{l}\text { Chumbo } \\
(\mathrm{Pb})\end{array}$ & $\begin{array}{c}272(68- \\
1836)\end{array}$ & $101(46-172)$ & $\begin{array}{c}310(108- \\
745)\end{array}$ & 30 a 75 & $\begin{array}{c}500(\mathrm{a}) ; 900(\mathrm{~b}) \\
\text { e } 150(\mathrm{c}, \mathrm{d})\end{array}$ \\
\hline Zinco (Zn) & $\begin{array}{c}583(312- \\
1425) \\
\end{array}$ & $561(409-747)$ & $\begin{array}{l}681(379- \\
975)\end{array}$ & 190 a 300 & $\begin{array}{c}1.500(\mathrm{a}, \mathrm{b}) \\
500(\mathrm{c}) \text { e } 400(\mathrm{~d})\end{array}$ \\
\hline
\end{tabular}


(1) (a) Brasil : Ministério da Agricultura, Pecuária e Abastecimento (MAPA), da portaria $n^{\circ} 49$ de 25/04/2005, Silva et al. (2002a) ; (b) Austrália; (c) Suíça e (d) Alemanha. (GROSSI, 1983).

A legislação do Brasil não estabelece limites para a quantidade relativa de coliformes fecais em composto de lixo urbano para uso agrícola, o que existe é a norma CETESB P.4.230 para o uso agrícola do lodo de esgoto, classificando-o em duas classes (A e B). O lodo considerado classe A deve apresentar densidade de coliformes fecais inferior a $1.000 \mathrm{NMP} / \mathrm{g}$; no lodo da classe $\mathrm{B}$, a densidade de coliformes fecais deve ser inferior a $2.000 .000 \mathrm{NMP} / \mathrm{g}$ e superior a $1.000 \mathrm{NMP} / \mathrm{g}$. O composto da Usina A apresenta um valor médio de coliforme fecais de $3.500 \mathrm{NMP} / \mathrm{g}$ de composto; comparando-se este valor com os limites estabelecidos pela norma 4.230 da Cetesb (1999), o composto é classificado como classe B. Os pré-compostos das usinas $\mathrm{C}$ e D também seriam enquadrados como classe B.

Tabela 2 - Características químicas e biológicas dos pré-compostos de lixo produzido no município de São Sebastião e de São Paulo, em comparação dos limites máximos do composto previstos nas legislações internacionais.

\begin{tabular}{cccc}
\hline Elementos & Usina A & Usinas C e D & $\begin{array}{c}\text { Limites máximos para } \\
\text { elementos nos } \\
\text { compostos }\end{array}$ \\
\hline Umidade, \% & 35 a 45 & 10 a 25 & $40-44$ (a) \\
Carbono total, \% & 15 a 14 & 20 a 35 & $18,0-21,0$ (a) \\
PH (água) & 7 a 7,5 & 5,5 a 7,5 & $>6,0$ ou $6,5(\mathrm{a})$ \\
Relação C/N & 16 a $14 / 1$ & 17 a $35 / 1$ & $15 / 1$ a $18 / 1$ (a) \\
$\begin{array}{c}\text { Inertes, \% } \\
\text { Mat.Orgânica, }\end{array}$ & -- & 10 a 13,5 & $5 \%(\mathrm{a})$ \\
$\%$ & 30 a 35 & 45 a 55 & 36 a $40 \quad(\mathrm{a})$ \\
$\begin{array}{c}\text { Coliformes } \\
\text { fecais (NMP/g) }\end{array}$ & 1.100 a 3.500 & 1.100 a 11.000 & $\begin{array}{c}\text { (Lodo class. } 1.000 \mathrm{~A} \mathrm{e} \\
\text { 2000 B/CET) }\end{array}$ \\
\hline
\end{tabular}

(a) Brasil : Portaria n ${ }^{\circ} 49$ do MAPA e Silva et al. (2002a); (b) Austrália; (c) Suíça e (d) Alemanha (PARR; HORNICK, 1992).

\section{CONCLUSÕES}

1. Sistema DANO tradicional utilizando em usina de processamento para a triagem do material inorgânico e produção do composto orgânico bioestabilizado: o sistema necessita que o composto permaneça no mínimo 50 dias nos pátios de maturação, com revolvimentos quinzenais devendo ser peneirados após esse tempo. O composto de lixo produzido por esse sistema possui maturação, 
disponibilidade de nutrientes, em especial fósforo e potássio, níveis de metais pesados e quantidade de materiais inertes adequados para o uso na agricultura.

2. Sistema DANO modificado: o material orgânico permanece no cilindro bioestabilizador por um período inferior a $8 \mathrm{~h}$, devido ao aumento da velocidade de rotação para se processar um maior volume de material ao mesmo tempo. Neste caso o material orgânico não sofre o processo de maturação em pátios e o peneiramento é parcial. Esse material é chamado de pré-composto e não pode ser considerado como um fertilizante orgânico. É inadequado para uso agrícola, pois não atingiu o ponto de maturação correto, com menores teores de nutrientes disponíveis, presença de materiais inertes e de vetores.

3. Sistema FABER AMBRA: não se caracteriza como usina de processamento e sim como um sistema de disposição do lixo em que a decomposição é acelerada por um sistema de aeração induzida. Embora possua boas condições de maturação com o composto produzido após um período de 6 a 9 meses de biodegradação e com a separação do material inorgânico inerte do material orgânico ativo não se recomenda seu uso agrícola pois, em função do processo de produção, apresenta teor alto do metal pesado cádmio, devido a grande quantidade de plásticos incluídos no processo tornando-se inviável seu uso sem uma triagem prévia do material utilizado no processo de produção.

\section{AGRADECIMENTOS}

A FAPESP pelo apoio financeiro à pesquisa.

\section{REFERÊNCIAS}

BARREIRA, L. P. Avaliação das usinas de compostagem do Estado de São Paulo em função da qualidade dos compostos e processos de produção. 2005. s.n. .Tese (Doutorado em Saúde Ambiental) - Faculdade de Saúde Pública. Universidade de São Paulo, São Paulo, 2005.

BIDONE, F. R.; POVINELLI, J. Conceitos básicos de resíduos sólidos. São Carlos: EESC/USP, 1999. 109 p.

CARLSSON, B. Especialistas apresentam tecnologias de tratamento do lixo de última geração. CG Notícias. Campo Grande: 01 jul. 2003. Disponível em: $<$ http://www.cgnoticias.ms.gov.br/index.htm? cont=noticias\&id=3557>. Acesso em: 24 out. 2005.

COMPANHIA DE TECNOLOGIA DE SANEAMENTO AMBIENTAL- CETESB. Aplicação de lodos sistemas de tratamento biológico em áreas agrícolas: critério 
para projeto e operação - Manual Técnico - Norma Técnica, P4.230... São Paulo, 1999. $32 \mathrm{p}$.

CHITOlina, J. C., Silva, F. C.; ABREU, M. F., PALMA, F. M. S.; CARMO, J. B. Decomposição da matéria orgânica de compostos de lixo urbano e posterior preparo de extratos nítrico-perclórico. Campinas: Embrapa Informática Agropecuária, 2001. 8 p. (Embrapa Informática Agropecuária. Circular Técnica, 1). Disponível em: $<$ http://www.cnptia.embrapa.br/modules/tinycontent3/content/2001/CIRCULA RTECNICA1 int.pdf>. Acesso em: 24 out. 2005.

COSTA, A. C. Produção de alface em cultivos sucessivos adubados com composto orgânico de lixo urbano e teor de metais pesados no solo e na planta. 1978. 77 f. Tese (Doutorado em Fitotecnia e Produção Vegetal) - Universidade Federal de Viçosa, Viçosa, 1978.

CRAVO, M. da S. Composto de lixo urbano como fonte de nutrientes e metais pesados para alface. 1995. 135 p. Dissertação (Doutorado em Energia Nuclear) Centro de Energia Nuclear na Agricultura, Universidade de São Paulo, Piracicaba,1995.

DEPARTAMENTO DE ENGENHARIA QUÍMICA - DEQ/UEM. Pilhas. Disponível em: http://www.deq.uem.br/JornalDEQ/Pilhas.htm> Acesso em: 30 jun. 2004.

EGREJA FILHO, F. B. Avaliação da ocorrência e distribuição química de metais pesados na compostagem de lixo domiciliar urbano. 1993. 176f. Tese (Mestrado em Agroquímica) - Universidade Federal de Viçosa, Viçosa, 1993.

GROSSI, M. G. de L. Avaliação da qualidade dos produtos obtidos de usinas de compostagem brasileiras de lixo doméstico através de determinação de metais pesados e substâncias orgânicas tóxicas. 1993. 222 f. Tese (Doutorado em Química Analítica) Instituto de Química, Universidade de São Paulo, São Paulo, 1993.

HE, X. T.; LOGAN, T. J.; TRAINA, S. J. Physical and chemical characteristics of selected U.S. municipal solid waste composts. Journal of Environmental Quality, Madison, v. 24, p, 543-552, 1995.

HERNANDO, S.; LOBO, M. C.; POLO, A. Effect of the application of a municipal refuse compost on the physical and chemical proprieties of a soil. The Science of the Total Environment, Amsterdam, v. 81/82, p. 89-96, 1989. 
JAHNEL, M. C.; MELLONI, R.; CARDOSO, E. J. B. N. Maturidade de composto de lixo urbano. Scientia Agricola, Piracicaba, v. 56, n. 2, p. 301-304, abr./jun., 1999. Disponível

$<$ http://www.scielo.br/scielo.php?script=sci_arttext\&pid=S010390161999000200007 $\& \operatorname{lng}=$ en\&nrm=iso $>$. Acesso em: 24 out. 2005 .

KIEHL, E.J. Fertilizantes orgânicos. Piracicaba: Agronômica Ceres, 2003. 492 p.

LIBAULT, A. Os quatro níveis da pesquisa geográfica. Métodos em Questão, São Paulo, n. 1, p.1-12, 1971.

MELO, W. J., SILVA, F. C., MARQUES, M. O.; BOARETTO, A. E. Critérios para o uso de resíduos sólidos urbanos na agricultura e impactos ambientais. In: CONGRESSO BRASILEIRO DE CIÊNCIAS DO SOLO, 26., 1997, Rio de Janeiro. Anais... Viçosa, MG: Sociedade Brasileira de Ciência do Solo, 1997. 23 p. 1 CDRom. Seção 9.

PARR, J. F.; HORNICK, S. B. Agricultural use of organic amendments: a historical perspective. American Journal of Alternative Agriculture, Greenbelt, v. 7, n. 4, p. 181-189, 1992.

SILVA, A. F. S. Influência da aplicação de composto de lixo urbano na cana-deaçúcar (Saccharum spp) e na fertilidade do solo. 1999. 70 f. Dissertação (Mestrado em Ciência Tecnologia dos Alimentos) - Escola Superior de Agricultura "Luiz de Queiroz", Universidade de São Paulo, Piracicaba. 1999.

SILVA, F. C., BERTON, R. S., CHITOLINA, J. C.; BALESTEIRO, S. D. Uso agrícola do composto de lixo no Estado de São Paulo: recomendações técnicas. Campinas: Embrapa Informática Agropecuária, 2002a. (Embrapa Informática Agropecuária. Circular Técnica da Embrapa Informática Agropecuária, 3). Disponível em: http://www.cnptia.embrapa.br/modules/tinycontent3/content/2002/circtec3.pdf. Acesso em: 24 out. 2005.

SILVA, F. C., COSTA, F. O., ZUTIN, R., RODRIGUES, L. H., BERTON, S. B.; SILVA, A. E. A. Sistema especialista para aplicação do composto de lixo urbano na agricultura. Campinas: Embrapa Informática Agropecuária, 2002b. (Embrapa Informática Agropecuária. Documentos, 28). Disponível em: $<$ http://www.cnptia.embrapa.br/modules/tinycontent3/content/2002/doc22.pdf $>$. Acesso em: 24 out. 2005. 
UNIVERSIDADE ESTADUAL DE MARINGÁ. Departamento de Engenharia Química - EM/DEQ. Pilhas. Disponível em: <http://www.deq.uem.br/JornalDEQ/Pilhas.htm>. Acesso em: 24 out. 2004.

VOIGTEL, S. S. D. Uso agrícola do material bioestabilizado resultante do tratamento mecânico-biológico (Sistema FABER-AMBRA) aplicado aos resíduos domiciliares do município de São Sebastião-SP. 2002. 48 f. Trabalho de Conclusão de Curso (Especialização em Gerenciamento de Resíduos Urbanos e Industriais) - Departamento de Ciências Agrárias, Universidade de Taubaté, Taubaté, 2002.

WEIR, C. C.; ZEIGER, E. Effects of using organic wastes as soil amendments in urban horticultural pratices in the District of Columbia. Journal Environmental Science Health, Parte B, Pesticides, Food Contaminants, New York, v. 32, p. 323332, 1997.

XIN, T. H.; THAINA, S. J.; LOGAN, T. J. Chemical properties of municipal solid waste compost. Journal of Environmental Quality, Madison, v. 21, n. 3., p. 318-329, 1992. 